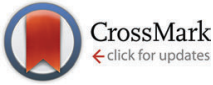

Cite this: Phys. Chem. Chem. Phys., 2015, 17, 11490

Received 16th January 2015, Accepted 27th March 2015

DOI: $10.1039 / \mathrm{c5cp00269a}$

www.rsc.org/pccp

\title{
Efficient size control of copper nanoparticles generated in irradiated aqueous solutions of star-shaped polyelectrolyte containers
}

\author{
Alexey A. Zezin, ${ }^{\text {ab }}$ Vladimir I. Feldman, ${ }^{a}$ Sergei S. Abramchuk, ${ }^{a}$ Gurgen V. Danelyan, ${ }^{b}$ \\ Victor V. Dyo, ${ }^{b}$ Felix A. Plamper, ${ }^{c}$ Axel H. E. Müller ${ }^{d}$ and Dmitry V. Pergushov*a
}

\begin{abstract}
The formation of copper nanoparticles (Cu-NPs) in irradiated aqueous solutions of star-shaped poly(acrylic acid) (PAA) were studied at two $\mathrm{pH}$ values. Transmission electron microscopy (TEM) demonstrates that the star-shaped macromolecules loaded with $\mathrm{Cu}^{2+}$ ions can act as individual nanosized containers providing a perfect control over the size and size distribution of Cu-NPs. Electron paramagnetic resonance (EPR) and optical spectroscopy show a transformation of mechanisms controlling the reduction of $\mathrm{Cu}^{2+}$ ions and the further formation of Cu-NPs. At $\mathrm{pH}$ 2.9, Cu-NPs are formed from the aquacomplexes of $\mathrm{Cu}^{2+}$ ions through homogeneous nucleation. At pH 4.3, the formation of Cu-NPs occurs inside macromolecular containers loaded with $\mathrm{Cu}^{2+}$ ions, which are bound to carboxylic groups of the polyelectrolyte. In the latter case, $\mathrm{Cu}$-NPs apparently ripen from preformed hydrated $\mathrm{Cu}_{2} \mathrm{O}$ seeds, which are thought to result from the ultrasmall $\left(\mathrm{Cu}^{2+}\right)_{m}\left(\mathrm{OH}^{-}\right)_{k}\left(\mathrm{COO}^{-}\right)_{n}$ species, thus implying a heterogeneous nucleation.
\end{abstract}

\section{Introduction}

The design of catalytic systems with extremely high specific surface area, advanced medicines and drug delivery systems, or nanosized magnetic materials has stimulated an ever-increasing interest in metallo-containing nanoparticles (NPs) obtained in polymer-based scaffolds. In particular, they could be prepared through reduction of metal ions bound to ionic groups on polyelectrolytes. $^{1-6}$ Besides their well-known stabilizing effect, the polyelectrolyte-based matrices can also play a structureforming role, thereby providing a fine tool for efficient control of the formation of the generated metallo-containing NPs as well as of their properties.

During the last few years, various advanced ionic polymer architectures (including microgels, ${ }^{7,8}$ spherical polyelectrolyte brushes, ${ }^{3,4,6}$ micelles of ionic amphiphilic block co- or terpolymers, ${ }^{1,9-12}$ ionic dendrimers, ${ }^{13,14}$ star-shaped polyelectrolytes ${ }^{15,16}$ and cylindrical polyelectrolyte brushes ${ }^{17}$ ) were demonstrated as suitable templates for the fabrication of nanosized inorganic-polymer hybrids. Here,

\footnotetext{
${ }^{a}$ Department of Chemistry, M.V. Lomonosov Moscow State University, Leninskie Gory 1/3, 119991 Moscow, Russia. E-mail: aazezin@yandex.ru, pergush@genebee.msu.ru

${ }^{b}$ Institute of Synthetic Polymer Materials, a foundation of Russian Academy of Sciences, Profsoyuznaya st. 70, 117393 Moscow, Russia

${ }^{c}$ Institute of Physical Chemistry, RWTH Aachen University, Landoltweg 2, 52056 Aachen, Germany

${ }^{d}$ Institute of Organic Chemistry, Johannes Gutenberg University of Mainz, Duesbergweg 10-14, 55099 Mainz, Germany
}

the ionic polymer species are considered as scaffolds for the reduction of metal ions and further as hosts stabilizing the formed metallo-containing NPs. Furthermore, liquid-based methods of reduction conventionally applied in this case provide a precise tuning of nucleation and growth steps of the NPs via manipulation of thermodynamic (e.g., temperature, reduction potential) and kinetic (reaction rate and reagents transport) parameters. Despite the considerable progress in the field, empirical treatments are often used for preparation of such composite nanostructures. Moreover, features and peculiarities of the assembly process generating the metallo-containing NPs in polyelectrolyte-based systems as well as the mechanism of their growth are still poorly understood and, to date, remain mostly unclear.

Obviously, star-shaped polyelectrolytes (also referred to as polyelectrolyte stars $)^{18-20}$ can be used as nanosized containers for the incorporation of metal ions and further as scaffolds in the preparation of metallo-containing NPs with tunable sizes and preferably with controlled size distribution. To the best of our knowledge, however, there are only a few reports on the reduction of metal ions in such systems. ${ }^{15,16}$ This paper considers the reduction of $\mathrm{Cu}^{2+}$ ions in an aqueous solution of star-shaped poly(acrylic acid) (PAA) as carboxylate groups are suitable for complexing with $\mathrm{Cu}^{2+}$ and are good stabilizers for the resultant NPs. ${ }^{5,21-25}$ In particular, we demonstrate that the star-shaped topology of the polyelectrolyte is a prerequisite for the formation of copper NPs (Cu-NPs) with a narrow size distribution while their mean size is determined by the molecular weight of the PAA star. The interest in Cu-NPs is mainly 
motivated by their pronounced fungicide and antibacterial characteristics $^{26,27}$ as well as (electro)catalytic properties. ${ }^{23,24,28}$ Other important applications of $\mathrm{Cu}$-NPs are related to optical materials and surface-enhanced Raman scattering ${ }^{29,30}$ or conductive inks. $^{31}$

Ionizing irradiation can be applied for reduction of metal ions. One of the advantages of this technique over the common chemical reduction is the easy preparation of metal NPs due to high reduction potentials of radiolysis products. ${ }^{32,33}$ This is especially important for transition metal ions, reduction of which to metal NPs requires very strong reduction agents. ${ }^{32,33}$ In particular, the successful synthesis of Cu-NPs through $\gamma$-irradiation of aqueous solutions of $\mathrm{Cu}^{2+}$ ions in the presence of various water-soluble polymers or surfactants was reported. ${ }^{34}$ We have already applied different types of ionizing irradiation (X-rays, electron beam, $\gamma$-irradiation) for the reduction of $\mathrm{Cu}^{2+}$ ions to $\mathrm{Cu}$-NPs in various polyelectrolyte-based matrices. ${ }^{5,21,22,25}$ Another advantage is the possibility of achieving control of different stages of the reduction process and the formation of NPs via varying irradiation conditions, e.g., exposition and dose rate. ${ }^{32,33,35}$

The ultimate purpose of our work is to study the assembly process generating $\mathrm{Cu}-\mathrm{NPs}$ from $\mathrm{Cu}^{2+}$ ions in aqueous solutions of star-shaped PAAs differing in the number of arms under different conditions: (i) when the metal ions exist as aquacomplexes and (ii) when they are bound to carboxylic groups of the polyelectrolyte. The different degrees of binding of $\mathrm{Cu}^{2+}$ ions to the PAA stars were achieved through the variation in the $\mathrm{pH}$ of their aqueous solutions.

\section{Experimental section}

\section{Materials}

Well-defined star-shaped poly(acrylic acid) $\left(\left(\mathrm{PAA}_{N}\right)_{X}\right.$, with $N$ and $X$ indicating the number-average degree of polymerization and the number of arms, respectively) with $N=90$ and $X=5$ $\left(\left(\mathrm{PAA}_{90}\right)_{5}, M_{\mathrm{n}}=36900 \mathrm{~g} \mathrm{~mol}^{-1}, D=1.04\right)$ and $N=100$ and $X=$ $21\left(\left(\mathrm{PAA}_{100}\right)_{21}, M_{\mathrm{n}}=161500 \mathrm{~g} \mathrm{~mol}^{-1}, D=1.02\right)$ as well as linear PAA with $M_{\mathrm{n}}=36000 \mathrm{~g} \mathrm{~mol}^{-1}(N=500, D=1.1)$ was synthesized and characterized as described elsewhere. ${ }^{18,20}$ Low-molecularweight compounds $\mathrm{CuSO}_{4} \cdot 5 \mathrm{H}_{2} \mathrm{O}$ and ethanol (all of the analytical grade) as well as $\mathrm{NaOH}$ (0.1 M standard titre solution) were used as received. Distilled water was used as the solvent.

\section{Sample preparation}

Sample solutions of star-shaped and linear PAAs containing $\mathrm{Cu}^{2+}$ ions were prepared by mixing 0.028 base-molar (that is, by the concentration of ionizable groups of the polyelectrolyte) stock solutions of the corresponding PAAs with $\mathrm{pH}$ adjusted to different values i.e., 2.9, 5.3, and 6.2 (a variation of the $\mathrm{pH}$ was achieved by addition of $0.1 \mathrm{M} \mathrm{NaOH}$ ) with $0.014 \mathrm{M}$ solution of $\mathrm{CuSO}_{4} \cdot 5 \mathrm{H}_{2} \mathrm{O}$. Correspondingly, the pH-values of the sample solutions after mixing were equal to $2.9,3.6$, and 4.3. The decrease of their $\mathrm{pH}$ is due to complexation of $\mathrm{Cu}^{2+}$ ions with - $\mathrm{COOH}$ groups, which is accompanied by a concomitant release of protons:

$$
\mathrm{Cu}^{2+}+2-\mathrm{COOH} \leftrightarrows \mathrm{Cu}^{2+}\left(-\mathrm{COO}^{-}\right)_{2}+2 \mathrm{H}^{+}
$$

The final concentration of carboxylic groups in the sample solutions was $0.014 \mathrm{M}(0.1 \mathrm{wt} \%)$ while the molar ratio $\left[\mathrm{Cu}^{2+}\right]$ : $[-\mathrm{COOH}]$ was always maintained at $3: 7$ to avoid $\mathrm{Cu}^{2+}$-induced aggregation of macromolecules of the PAAs. Prior to irradiation, ethanol (10 vol\%) was added to the sample solutions as a hydroxyl radical scavenger.

\section{Methods and instrumentation}

An X-ray unit with a 5-BKhV-6 $\mathrm{W}$ tube with a tungsten anode was used for irradiation. The effective energy of the X-ray radiation was $c a .22 \mathrm{keV}$. To avoid oxidation of Cu-NPs by air oxygen dissolved in the water-ethanol medium, the sample solutions were bubbled with argon of a special purity grade. Irradiation of the sample solutions was carried out at $293 \mathrm{~K}$.

A Perkin-Elmer Lambda 9 UV-VIS spectrometer (scanning range of 200-900 $\mathrm{nm}$ ) was used for monitoring the reduction of $\mathrm{Cu}^{2+}$ ions and the formation of $\mathrm{Cu}-\mathrm{NPs}$. The optical length of the used quartz cuvettes was $1 \mathrm{~mm}$. The state of $\mathrm{Cu}^{2+}$ ions in solutions of star-shaped (and linear) PAAs was studied by optical spectroscopy as well as by electron paramagnetic resonance (EPR) spectroscopy (X-band spectrometer with a $100 \mathrm{kHz}$ high frequency modulation manufactured by St. Petersburg Instrument (Russia)). A crystal made of synthetic ruby $\left(\mathrm{Al}_{2} \mathrm{O}_{3}\right.$ doped with $\mathrm{Cr}^{3+}$ ions) mounted inside the resonator cavity was used as the internal standard for the EPR signal intensity.

Information about the shape and the size/size distribution of Cu-NPs was obtained using a Leo-912 AB OMEGA transmission microscope (in microdiffraction mode) having a resolution of $0.25 \mathrm{~nm}$. The interplane distances were calculated by comparing the diameters of sample reflections with those of the reference sample (gold). The samples for transmission electron microscopy (TEM) measurements were prepared by casting on the grids from irradiated sample solutions. To prevent the postirradiation oxidation of Cu-NPs and other intermediate species, the casting of the samples for TEM and transfer of solutions to optical cells for UV-VIS spectroscopy were carried out under argon.

The absorbed dose rate was $11.9 \mathrm{~Gy} \mathrm{~s}^{-1}$, as measured using a ferrosulfate dosimeter. For polymer solutions containing $\mathrm{Cu}^{2+}$ ions, the dose rate was calculated taking into account the mass absorption coefficients and effective energy of X-rays. ${ }^{36}$

The average hydrodynamic diameters of PAA macromolecules in their aqueous mixtures with $\mathrm{Cu}^{2+}$ ions were measured using a NPA152-31A Zetatrac device equipped with a laser $(\lambda=780 \mathrm{~nm})$ as the light source.

\section{Results}

\section{Complexation of copper ions with poly(acrylic acid) stars}

The complexation of $\mathrm{Cu}^{2+}$ ions with -COOH groups of PAA is an equilibrium process, which shifts to the right upon increasing the $\mathrm{pH}$ (Scheme 1). The UV-VIS spectra of mixtures of PAA and $\mathrm{CuSO}_{4}$ measured at $\mathrm{pH} 2.9$ (Fig. 1, spectrum 1) and $\mathrm{pH} 4.3$ (Fig. 1, spectrum 2) provide clear evidence that at the lower $\mathrm{pH}$-value ( $\mathrm{pH}$ 2.9) $\mathrm{Cu}^{2+}$ ions exist in the form of aquacomplexes (weak band with a maximum at ca. $812 \mathrm{~nm}$ ) while they form 


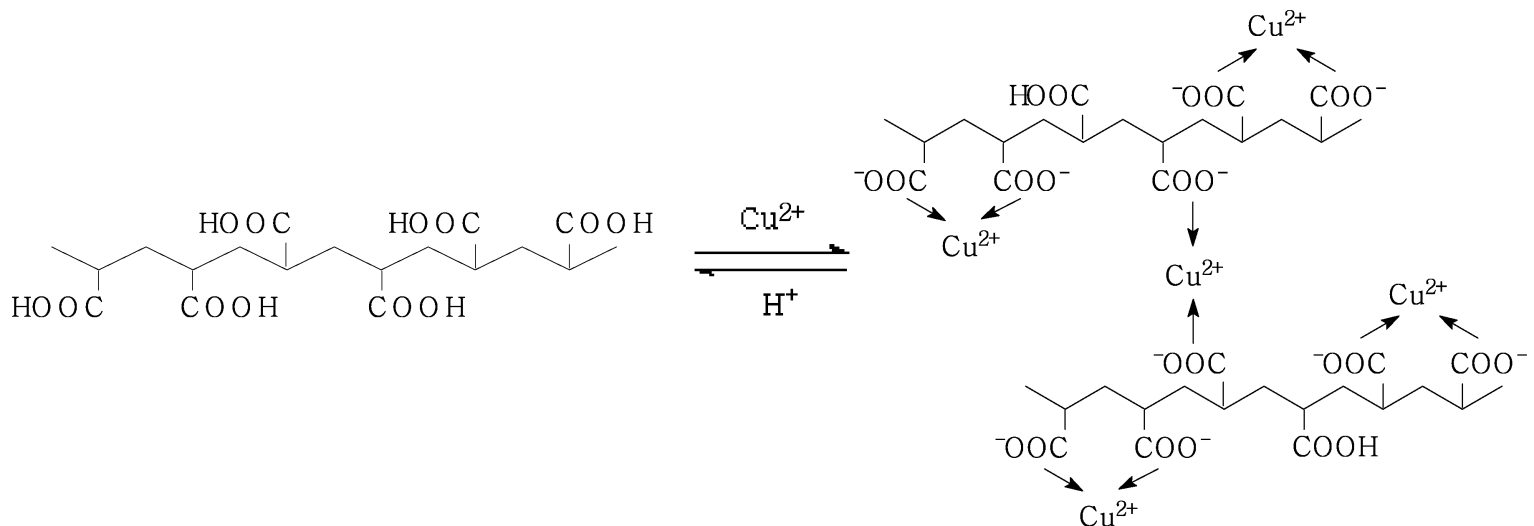

Scheme 1 Schematic representation of the interaction of $\mathrm{Cu}^{2+}$ ions with PAA stars with different segments belonging to the same or different arms.

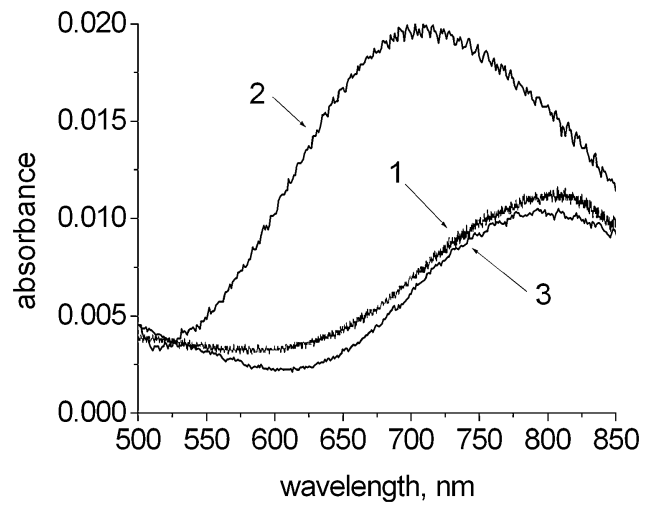

Fig. 1 The UV-VIS spectra of aqueous mixtures of $\left(\mathrm{PAA}_{90}\right)_{5}$ and $\mathrm{CuSO}_{4}$ at $\mathrm{pH} 2.9$ (1) and at $\mathrm{pH} 4.3$ (2). UV-VIS spectrum of an aqueous solution of $\mathrm{CuSO}_{4}$ at $\mathrm{pH} 4.3$ (3) is given as a reference. The concentrations of carboxylic groups and $\mathrm{Cu}^{2+}$ ions in the sample solutions were $0.014 \mathrm{M}$ and $0.006 \mathrm{M}$, respectively.

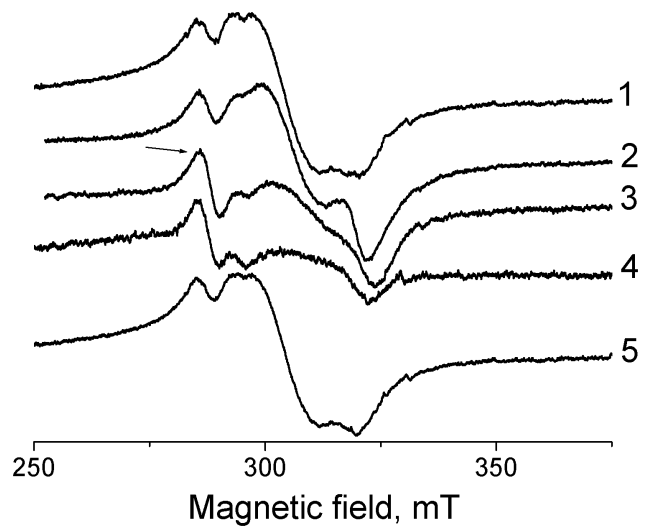

Fig. 2 The EPR spectra of a frozen aqueous solution of $\mathrm{CuSO}_{4}$ at $\mathrm{pH} 2.9$ (1), frozen aqueous mixtures of the $\left(\mathrm{PAA}_{90}\right)_{5}$ and $\mathrm{CuSO}_{4} \mathrm{pH} 2.9$ (2), $\mathrm{pH} 3.6$ (3), $\mathrm{pH} 4.3$ (4), and a frozen aqueous solution of $\mathrm{CuSO}_{4}$ at $\mathrm{pH} 4.3$ (5). The signal from the internal standard is marked by an arrow. The concentrations of carboxylic groups and $\mathrm{Cu}^{2+}$ ions in the sample solutions were $0.014 \mathrm{M}$ and $0.006 \mathrm{M}$, respectively.

complexes with $-\mathrm{COO}^{-}$groups of PAA (intense band with a maximum at $c a .714 \mathrm{~nm}$ ) at the higher $\mathrm{pH}$-value ( $\mathrm{pH} \mathrm{4.3).}$
The EPR spectra obtained for the frozen aqueous mixtures of PAA stars and $\mathrm{CuSO}_{4}$ at different pH-values (Fig. 2, spectra 2-4) prove this inference. At the given molar ratio of $\left[\mathrm{Cu}^{2+}\right]$ : $[-\mathrm{COOH}]=3: 7$, EPR spectroscopy demonstrated that $\mathrm{Cu}^{2+}$ ions are complexed with two carboxylate groups. ${ }^{37}$ It should be noted that the spectra given in Fig. 2 are poorly resolved due to the high concentration of paramagnetic species. Nevertheless, their shape is characteristic of the ligand environment of $\mathrm{Cu}^{2+}$ ions. The spectra of the frozen $\mathrm{CuSO}_{4}$ solution (spectra 1 and 5) exhibit a broad anisotropic pattern with $g_{\perp} \approx 2.08$ and a poorly resolved four-line hyperfine structure in accordance with published data. ${ }^{38}$ In the presence of the PAA stars, the parameters of the EPR signal change, indicating that $\mathrm{Cu}^{2+}$ ions complex with carboxylate groups (anisotropic signal with $g_{\perp}=$ $2.06^{37}$ ). The increasing pH (Fig. 2, spectra 2-4) leads to the redistribution of $\mathrm{Cu}^{2+}$ ions from bulk solution toward the PAA stars. Thus, comparison of integrated intensities of EPR signals suggests that at $\mathrm{pH} 2.9$ more than $90 \%$ of $\mathrm{Cu}^{2+}$ ions are in the form of an aquacomplex whereas the opposite case is observed at $\mathrm{pH} 4.3$, that is, $\mathrm{Cu}^{2+}$ ions are mainly (more than 90\%) complexed with $-\mathrm{COO}^{-}$groups of the PAA stars.

It is remarkable that the average hydrodynamic diameters of macromolecules of both star-shaped PAAs, $\left(\mathrm{PAA}_{90}\right)_{5}$ and $\left(\mathrm{PAA}_{100}\right)_{21}$, in solutions with concentration of $0.2 \mathrm{wt} \%$ in the presence of $\mathrm{Cu}^{2+}$ ions $\left(\left[\mathrm{Cu}^{2+}\right]:[-\mathrm{COOH}]=3: 7\right)$ are within $10-15 \mathrm{~nm}$, thereby indicating their molecularly dispersed state and the absence of intermacromolecular association through bridging with $\mathrm{Cu}^{2+}$ ions.

\section{Formation of copper nanoparticles in irradiated solutions of poly(acrylic acid) stars}

Optical spectra of irradiated aqueous mixtures of $\left(\mathrm{PAA}_{N}\right)_{X}$ and $\mathrm{CuSO}_{4}$ exhibit the decrease in the intensities of the bands of both $\mathrm{Cu}^{2+}$ ions present as aquacomplexes (maximum at $812 \mathrm{~nm}$ ) and $\mathrm{Cu}^{2+}$ ions complexed with the carboxylic groups of PAA stars (maxima at 249 and $714 \mathrm{~nm}$ ). This clearly manifests the reduction of $\mathrm{Cu}^{2+}$ ions. Fig. 3 shows the changes in the concentration of $\mathrm{Cu}^{2+}$ ions with the irradiation dose, the content of $\mathrm{Cu}^{2+}$ ions being derived from the optical spectra at the above-indicated absorbance maxima. It should be noted that the increasing solution turbidity does not allow us to 

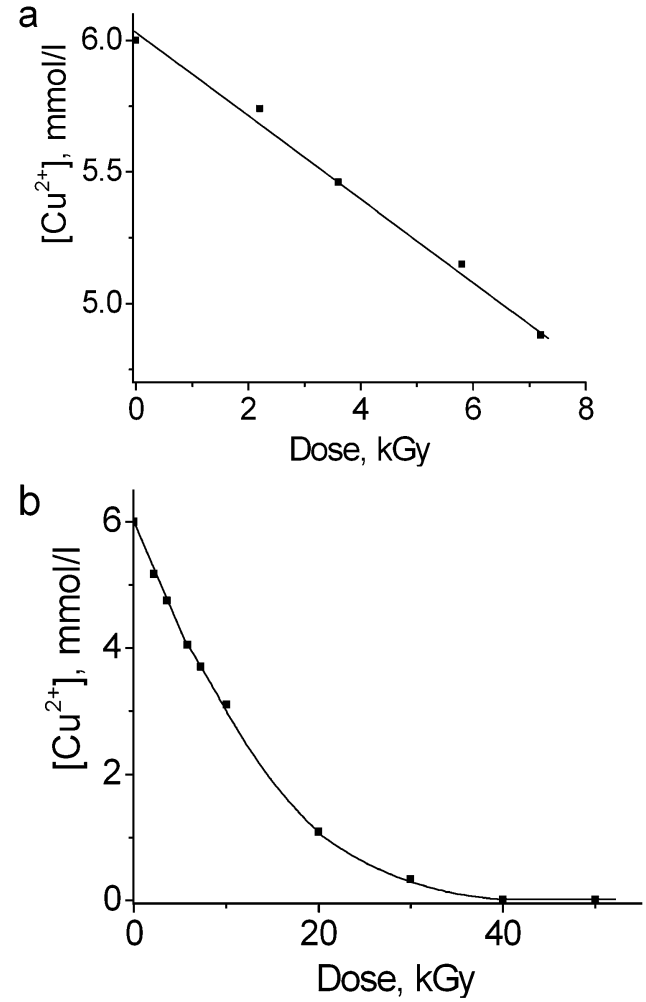

Fig. 3 The effect of irradiation dose on the molar concentration of $\mathrm{Cu}^{2+}$ ions in aqueous mixtures of $\left(\mathrm{PAA}_{90}\right)_{5}$ and $\mathrm{CuSO}_{4}$ at $\mathrm{pH} 2.9$ (a) and $\mathrm{pH} 4.3$ (b). The concentrations of carboxylic groups and $\mathrm{Cu}^{2+}$ ions in the sample solutions were $0.014 \mathrm{M}$ and $0.006 \mathrm{M}$, respectively.

quantitatively estimate the effect of irradiation on the concentration of $\mathrm{Cu}^{2+}$ ions at $\mathrm{pH} 2.9$ for the doses above $10 \mathrm{kGy}$. The radiolytic reduction yields were calculated from the UV-VIS spectra using the absorbance intensities at $812 \mathrm{~nm}(\mathrm{pH} 2.9)$ and $249 \mathrm{~nm}$ (pH 4.3) as these bands do not overlap with the absorptions from other species. The values of the radiation-chemical yields were found to be 1.4 and 4.4 species per $100 \mathrm{eV}$ of the absorbed energy for the sample solutions at $\mathrm{pH} 2.9$ and 4.3 , respectively.

Fig. 4 shows the evolution of the UV-VIS spectra of $\mathrm{Cu}^{2+}$ ions in solutions of $\left(\mathrm{PAA}_{90}\right)_{5}$ at $\mathrm{pH} 2.9$ (Fig. 4a) and at pH 4.3 (Fig. 4b). Irradiation of $\mathrm{Cu}^{2+}$ ions at $\mathrm{pH} 2.9$ (dose $20 \mathrm{kGy}$ ) results in the red coloration of their solutions, the absorbance band near $570 \mathrm{~nm}$ (indicated by an arrow) appears in the UV-VIS spectrum (Fig. 4a). In addition, this spectrum demonstrates a strong Raleigh scattering (masking the absorbance band at $570 \mathrm{~nm}$ ) as the system becomes turbid after irradiation. After irradiation of $\mathrm{Cu}^{2+}$ ions in solutions of $\left(\mathrm{PAA}_{90}\right)_{5}$ at $\mathrm{pH} 4.3$ (dose $20 \mathrm{kGy}$ ), the red coloration and the intense absorbance band near $570 \mathrm{~nm}$ (indicated by an arrow) are observed (Fig. 4b). Spectrum 4 for the sample irradiated up to a dose of $40 \mathrm{kGy}$ (the absorbance band with a maximum at $563 \mathrm{~nm}$ and the broad absorbance band at $350-450 \mathrm{~nm}$ ) given in the same figure corresponds to the experimental and the calculated spectra of $\mathrm{Cu}-\mathrm{NPs}{ }^{33,39}$ Irradiation of $\mathrm{Cu}^{2+}$ ions in solutions of $\left(\mathrm{PAA}_{100}\right)_{21}$ and linear PAA leads to the same evolution of their UV-VIS spectra.

For a TEM study, the sample solutions irradiated at $40 \mathrm{kGy}$ were used. The obtained images (Fig. 5a, c and 6a, c) demonstrate NPs in
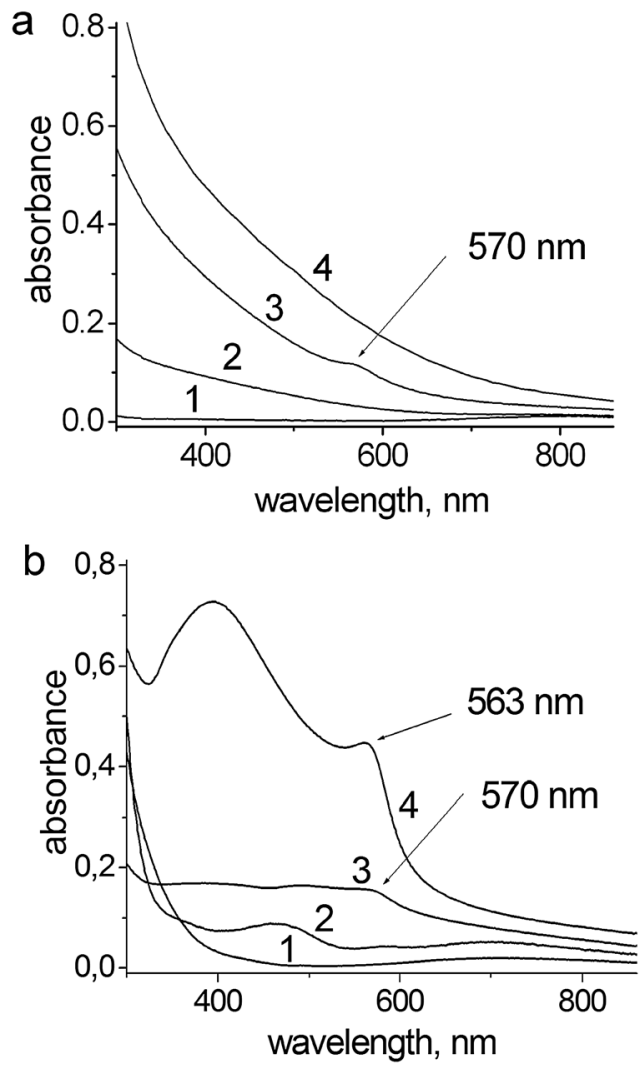

Fig. 4 The UV-VIS spectra of aqueous mixtures of $\left(\mathrm{PAA}_{90}\right)_{5}$ and $\mathrm{CuSO}_{4}$ irradiated up to a dose of $\mathrm{O}$ (1), 10 (2), 20 (3), and 40 (4) kGy; (a) at pH 2.9 and (b) at $\mathrm{pH}$ 4.3. The concentrations of carboxylic groups and $\mathrm{Cu}^{2+}$ ions in the sample solutions were $0.014 \mathrm{M}$ and $0.006 \mathrm{M}$, respectively.
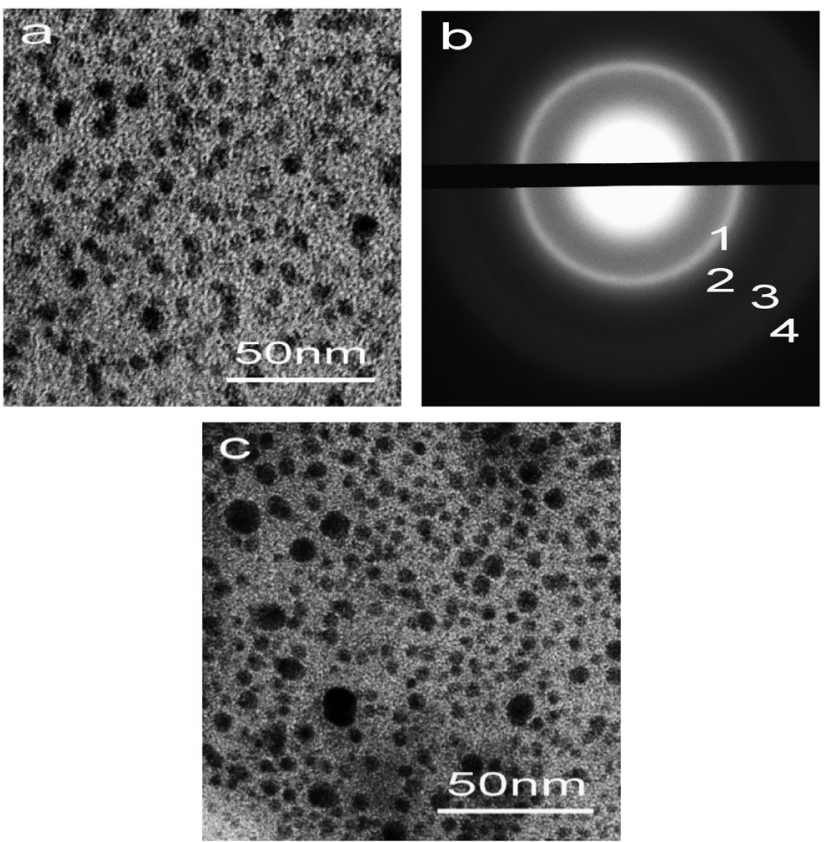

Fig. 5 The TEM image (a) and the microdiffractogram (b) of the irradiated (dose $40 \mathrm{kGy}$ ) aqueous mixture of $\left(\mathrm{PAA}_{90}\right)_{5}$ and $\mathrm{CuSO}_{4}$ at $\mathrm{pH}$ 2.9. The TEM image (c) of the irradiated (dose $40 \mathrm{kGy}$ ) aqueous mixture of the linear PAA and $\mathrm{CuSO}_{4}$ at $\mathrm{pH} 4.3$. The concentrations of carboxylic groups and $\mathrm{Cu}^{2+}$ ions in the sample solutions were $0.014 \mathrm{M}$ and $0.006 \mathrm{M}$, respectively. 


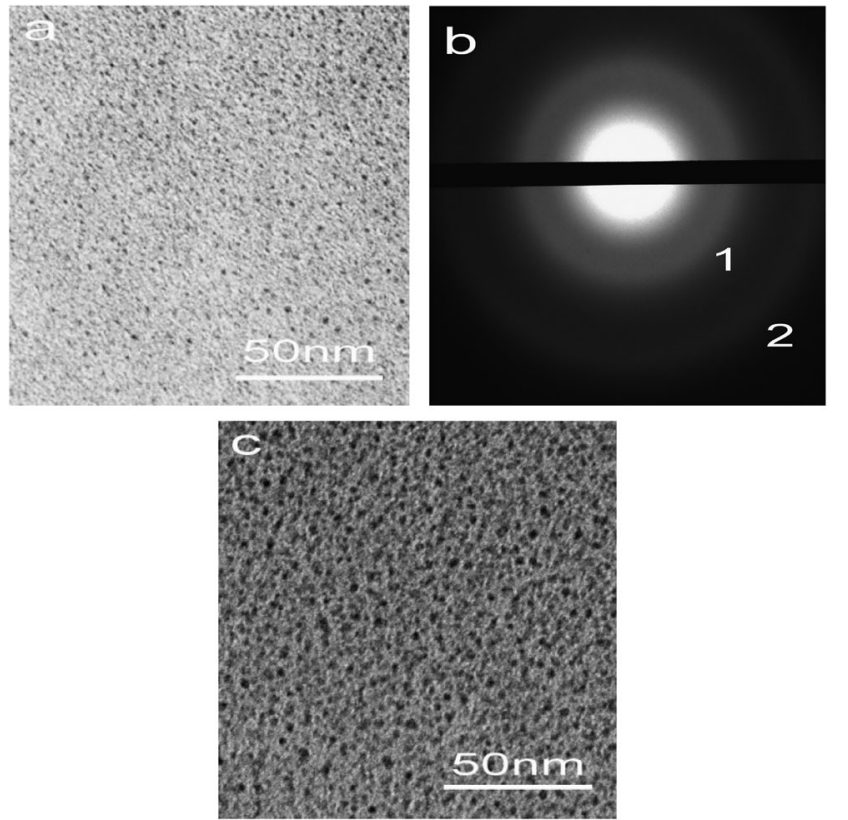

Fig. 6 The TEM image (a) and microdiffractogram (b) of the irradiated (dose $40 \mathrm{kGy}$ ) mixture of $\left(\mathrm{PAA}_{90}\right)_{5}$ and $\mathrm{CuSO}_{4}$ at $\mathrm{pH}$ 4.3. The TEM image (c) of the irradiated (dose $40 \mathrm{kGy}$ ) mixture of $\left(\mathrm{PAA}_{100}\right)_{21}$ and $\mathrm{CuSO}_{4}$ at $\mathrm{pH} 4.3$. The concentrations of carboxylic groups and $\mathrm{Cu}^{2+}$ ions in the sample solutions were $0.014 \mathrm{M}$ and $0.006 \mathrm{M}$, respectively.

the irradiated mixtures of star-shaped and linear PAAs and $\mathrm{CuSO}_{4}$. For the mixture of $\left(\mathrm{PAA}_{90}\right)_{5}$ and $\mathrm{CuSO}_{4}$ irradiated at $\mathrm{pH}$ 2.9, the microdiffractogram (Fig. 5b) shows the wide reflections 1, 2, 3, and 4 that correspond to interplanar distances $2.09,1.81,1.29$, and $1.09 \AA$, respectively. These values are in good agreement with known values of $2.08,1.81,1.28$ and $1.09 \AA$ for the copper lattice, ${ }^{40}$ thereby providing distinct evidence for the formation of Cu-NPs in the system.

At the same time, wide reflections corresponding to interplane distances of $c a$. 1.20 and $2.00 \AA$ (an intermediate position relative to the pairs of face-centered reflections of crystalline copper lattice) that are observed for mixtures of $\left(\mathrm{PAA}_{90}\right)_{5}$ and $\mathrm{CuSO}_{4}$ (Fig. 6b) irradiated at $\mathrm{pH} 4.3$ demonstrate only a short-range order of copper atoms while the formed NPs are smaller (Fig. 6a and c).

Fig. 7 gives the size distributions of Cu-NPs for different systems obtained from analysis of about 50-150 NPs in the TEM images given in Fig. 5 and 6. As one can see, the NPs prepared at $\mathrm{pH} 4.3$ are small and narrow-dispersed in their size. Indeed, Cu-NPs generated in the presence of $\left(\mathrm{PAA}_{90}\right)_{5}$ have a number-average diameter $D_{\mathrm{n}}$ of $c a .1 .1 \mathrm{~nm}$ (Fig. 7b) and $D_{\mathrm{w}} / D_{\mathrm{n}}=$ 1.01 ( $D_{\mathrm{w}}$ is a weight-average diameter). At the same time, $\mathrm{Cu}$ NPs obtained for the same system at pH 2.9 are larger, with a $D_{\mathrm{n}}$-value of $c a$. $3.4 \mathrm{~nm}$, and are characterized by a considerably broader size distribution with $D_{\mathrm{w}} / D_{\mathrm{n}}=1.13$ (Fig. 7a).

Furthermore, the star-shaped topology of PAA appears to decisively determine the size of $\mathrm{Cu}$-NPs and the width of their size distribution. The increasing number of arms leads to a larger size, the size distribution remaining narrow. In fact, the $\mathrm{Cu}$-NPs obtained in the presence of $\left(\mathrm{PAA}_{100}\right)_{21}$ at $\mathrm{pH} 4.3$ have a $D_{\mathrm{n}}$-value of $c a .2 .1 \mathrm{~nm}$ (Fig. $7 \mathrm{c}$ ) and $D_{\mathrm{w}} / D_{\mathrm{n}}=1.02$. In the limiting case of linear PAA, which forms aggregates upon complexation with $\mathrm{Cu}^{2+}$ ions (average hydrodynamic diameter is $c a .30 \mathrm{~nm}$ ),
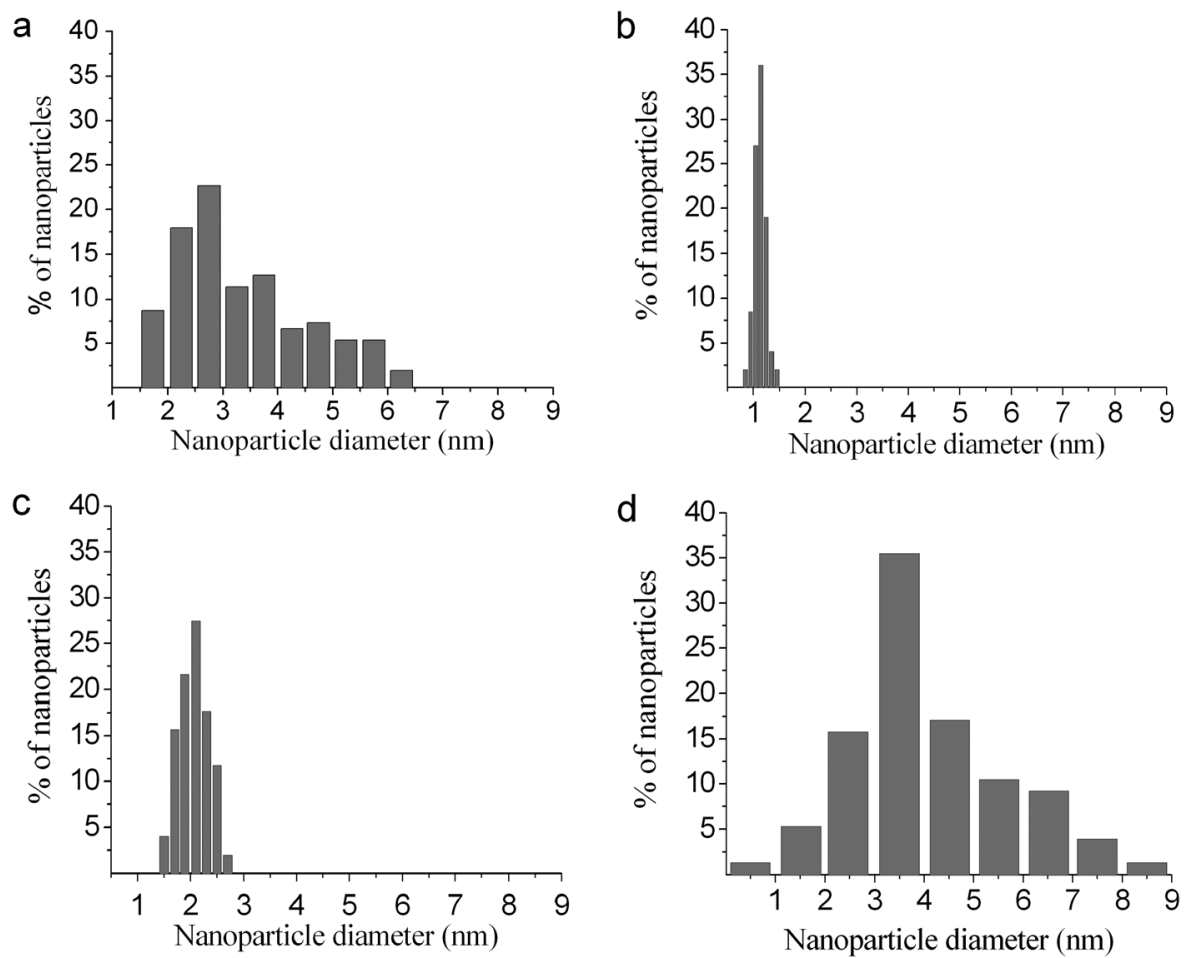

Fig. 7 The size distributions of $\mathrm{Cu}-\mathrm{NPs}$ obtained in the presence of $\left(\mathrm{PAA}_{90}\right)_{5}$ at $\mathrm{pH} 2.9$ (a), (PAA $\left.\mathrm{P}_{90}\right)_{5}$ at $\mathrm{pH} 4.3$ (b), $(\mathrm{PAA} 100)_{21}$ at pH 4.3 (c), and linear $\mathrm{PAA}$ at pH 4.3 (d). The concentrations of carboxylic groups and $\mathrm{Cu}^{2+}$ ions in the sample solutions were $0.014 \mathrm{M}$ and $0.006 \mathrm{M}$, respectively. 
the $D_{\mathrm{n}}$-value of the Cu-NPs being $c a .4 .1 \mathrm{~nm}$, is largest and the size distribution having $D_{\mathrm{w}} / D_{\mathrm{n}}=1.15$ is the broadest even at pH 4.3 (Fig. 7d).

\section{Discussion}

In polyelectrolyte-based systems, the active species used for the reduction of metal ions results mainly from radiolysis of water: ${ }^{32,33}$

$$
\mathrm{H}_{2} \mathrm{O} \leadsto \mathrm{e}^{-}{ }_{\mathrm{aq}}, \mathrm{OH}^{\bullet}, \mathrm{H}^{\bullet}, \mathrm{H}_{2}, \mathrm{H}_{2} \mathrm{O}_{2},
$$

where hydroxyl radicals $\mathrm{OH}^{\bullet}$ and hydrated electrons $\mathrm{e}^{-}$aq are the most important intermediates formed with the largest radiation-chemical yields (the bulk radiation-chemical yields are known to be $c a$. 2.8-2.9 species per $100 \mathrm{eV}^{33}$ ). Definitely, the reactions of $\mathrm{OH}^{\bullet}$ and $\mathrm{e}^{-}$aq play a dominating role in the system under study. The hydroxyl radicals act as oxidizing agents for metal atoms and ions in intermediate oxidation states. To increase the efficiency of the reduction processes, it is reasonable to use scavengers of the $\mathrm{OH}^{\bullet}$ species, e.g., aliphatic alcohols because the alcohol radicals act as reducing agents for metal ions and clusters. ${ }^{33,40}$

$$
\begin{gathered}
\mathrm{CH}_{3} \mathrm{CH}_{2} \mathrm{OH}+{ }^{\bullet} \mathrm{OH} \rightarrow \mathrm{CH}_{3}{ }^{\bullet} \mathrm{CHOH}+\mathrm{H}_{2} \mathrm{O} \\
\mathrm{CH}_{3} \cdot \mathrm{CHOH}+\mathrm{M}^{n+}+\mathrm{H}_{2} \mathrm{O} \leftrightarrows \mathrm{CH}_{3} \mathrm{CHO}+\mathrm{M}^{(n-1)+}+\mathrm{H}_{3} \mathrm{O}^{+}
\end{gathered}
$$

\section{Homogeneous nucleation}

In the case of homogeneous nucleation, the unstable charged clusters, which form at the initial stage of the reduction of metal ions in aqueous solution, are a source of the generated NPs. ${ }^{32,33}$ The cluster coagulation leads to larger particles until quasi-metal particles appear. The homogeneous nucleation includes the stages of (i) the formation of neutral metal atoms from isolated metal ions and (ii) the following aggregation of the metal atoms and ions into clusters. Remarkably, for atoms and clusters comprising a few atoms, reduction potentials are much more negative than those for the corresponding bulk metals. ${ }^{33}$ Hereto, reduction potentials for metal clusters change dramatically with increasing cluster sizes, becoming less negative for larger clusters. ${ }^{33,41}$

The radiation-induced reduction of $\mathrm{Cu}^{2+}$ ions in the presence of polyelectrolytes or water soluble macromolecules was described as a simple two-step process. ${ }^{33}$

$$
\mathrm{Cu}^{2+} \rightarrow \mathrm{Cu}^{+} \rightarrow \mathrm{Cu}^{0}
$$

Alternatively, it may include disproportionation of $\mathrm{Cu}^{+}$ions. ${ }^{42}$

$$
2 \mathrm{Cu}^{+} \rightarrow \mathrm{Cu}^{2+}+\mathrm{Cu}^{0}
$$

The formation of $\mathrm{Cu}$ clusters and $\mathrm{Cu}$-NPs occurs through the generation of metal atoms.

$$
\begin{aligned}
\mathrm{Cu}^{0}+\mathrm{Cu}^{2+} \rightarrow\left(\mathrm{Cu}_{2}\right)^{2+} & \rightarrow\left(\mathrm{Cu}_{4}\right)^{2+} \rightarrow\left(\mathrm{Cu}_{m}\right)^{n+} \\
\left(\mathrm{Cu}_{m}\right)^{n+}+\left(\mathrm{Cu}_{k}\right)^{g+} & \rightarrow\left(\mathrm{Cu}_{m+k}\right)^{(n+g)+}
\end{aligned}
$$

Obviously, all the radical reductants $\left(\mathrm{e}^{-}\right.$aq with a reduction potential of $-2.9 \mathrm{~V}$ and $\mathrm{CH}_{3}{ }^{\bullet} \mathrm{CHOH}$ with a reduction potential of $-1.5 \mathrm{~V}^{33}$ ) may react with $\mathrm{Cu}^{2+}$ ions to yield $\mathrm{Cu}^{+}$ones. The potential needed for reduction of $\mathrm{a} \mathrm{Cu}^{+}$ion to an isolated neutral copper atom $\mathrm{Cu}^{0}$ is extremely negative $(-2.7 \mathrm{~V}$ as estimated in ref. 33 and 43). Then, a crucial step in the preparation of $\mathrm{Cu}-\mathrm{NPs}$ is the formation of $\mathrm{Cu}^{0}$ atoms from $\mathrm{Cu}^{+}$ions in bulk solution. This occurs only due to a reaction in the presence of the strongest reducing agent (i.e., $\mathrm{e}^{-}$aq). ${ }^{33}$ Further processes include the formation of clusters $\mathrm{Cu}_{m}{ }^{n+}$ and, finally, Cu-NPs stabilized through the interaction with the ionic groups of PAA. ${ }^{5,18-22}$ Both active species and acetaldehyde (the stable product of irradiation) may act as reducing agents for larger clusters, thus resulting in the growth of the metal clusters and NPs. ${ }^{5,22,44}$

\section{Heterogeneous nucleation}

In the case of heterogeneous nucleation, the formation of metal NPs occurs from pre-existing seeds. The quasi-metal particles of intermediate size (8-15 atoms) with an interface then act as the nuclei for the metal phase due to their ability to reduce metal ions taken up. ${ }^{32} \mathrm{~A}$ facile, aqueous phase procedure has been developed for the synthesis of stable, polymer-coated Cu-NPs using polyallylamine as a capping agent and hydrazine as a reducing agent. ${ }^{30}$ The obtained results showed that $\mathrm{Cu}_{2} \mathrm{O}$ seeds were first formed at the beginning of the reduction process and then converted to Cu-NPs with a size of $30-50 \mathrm{~nm}$ as the reaction progressed. This requires the size of initial $\mathrm{Cu}_{2} \mathrm{O}$ particles to be within tens of nm. Despite the details of such processes being often unclear, the NP-assembly does not require such high negative potentials as in the case of homogeneous nucleation.

\section{Analysis of experimental results}

The experimental data demonstrate the influence of $\mathrm{pH}$ on the formation of Cu-NPs in irradiated aqueous mixtures of PAA and $\mathrm{CuSO}_{4}$. The pronounced effect of the $\mathrm{pH}$ on size characteristics of the NPs obtained in the presence of $\left(\mathrm{PAA}_{90}\right)_{5}$ (Fig. 7a and b) apparently traces back to the different states of $\mathrm{Cu}^{2+}$ ions in such solutions. At pH 2.9, they are present as aquacomplexes while being complexed with carboxylate groups at $\mathrm{pH}$ 4.3. Binding of $\mathrm{Cu}^{2+}$ ions with carboxylate groups of PAA, i.e., their localization within a volume occupied by a $\left(\mathrm{PAA}_{N}\right)_{X}$ macromolecule, causes the size of the Cu-NPs to decrease and their size distribution to narrow ( $c f$. Fig. 7a and b). Thus, in this case $\left(\mathrm{PAA}_{90}\right)_{5}$ stars in molecularly dispersed state act as individual nanosized containers for the formation of $\mathrm{Cu}-\mathrm{NPs}$, effectively controlling their sizes.

The experimental results also show that the topology (starshaped $v s$. linear) of the PAA macromolecules crucially determines the size/size distribution of the Cu-NPs. Indeed, a control of the size distribution of Cu-NPs in a solution of the linear PAA is rather poor (Fig. 7d): they are large and disperse in their size. Dynamic light scattering provides evidence that at $\mathrm{pH} 4.3$ chains of the linear PAA in the presence of $\mathrm{Cu}^{2+}$ ions form aggregates with average hydrodynamic diameter of $c a$. $30 \mathrm{~nm}$. In contrast, star-shaped PAAs being most probably present as individual macromolecules (average hydrodynamic 
diameter is within 10-15 $\mathrm{nm}$ ) provide a perfect control over the size distribution of Cu-NPs (Fig. 7b and c). We suggest that the PAA stars act as nanoreactors loaded with $\mathrm{Cu}^{2+}$ ions, which then are reduced to narrow-dispersed Cu-NPs with $D_{\mathrm{n}}$-values of $1.1 \mathrm{~nm}$ in the case of $\left(\mathrm{PAA}_{90}\right)_{5}$ (Fig. 7b) and $2.1 \mathrm{~nm}$ in the case of $\left(\mathrm{PAA}_{100}\right)_{21}$ (Fig. 7c). The capacity of such a nanoreactor is controlled by the number of functional groups of $\left(\mathrm{PAA}_{N}\right)_{X}$ stars, and are therefore proportional to the number of arms, $X$, and their length, $N$.

The isotropic Cu-NPs of sizes 1.1 and $2.1 \mathrm{~nm}$ include 120 and $630 \mathrm{Cu}$ atoms (nucleus) with an atomic radius of $0.128 \mathrm{~nm}$ correspondingly. In the case of the molar ratio $3: 7\left(\left[\mathrm{Cu}^{2+}\right]\right.$ : $[\mathrm{COOH}])$, the star-shaped macromolecules with 5 and 21 arms may include 190 and $900 \mathrm{Cu}^{2+}$ ions, which would form Cu-NPs with the size of 1.4 and $2.5 \mathrm{~nm}$, respectively. This finding demonstrates a direct correlation between the content of $\mathrm{Cu}^{2+}$ ions in $\left(\mathrm{PAA}_{N}\right)_{X}$ stars and the number of $\mathrm{Cu}$ atoms in the resulting NP. The differences between the estimated and the measured sizes of Cu-NPs may be explained by the fact that not all carboxylic groups of star-shaped PAAs might be accessible for the interaction with $\mathrm{Cu}^{2+}$ ions (due to, e.g., steric hindrance). Besides, one should take into account the fact that the accuracy of the size evaluation in TEM images is within $0.25 \mathrm{~nm}$. Thus, apparently all $\mathrm{Cu}^{2+}$ ions in one star-shaped macromolecule lead to only one $\mathrm{Cu}-\mathrm{NP}$, thereby resulting in a narrow size distribution of the NPs. At the same time, chains of the linear PAA in the presence of $\mathrm{Cu}^{2+}$ ions form ill-defined aggregates (average hydrodynamic diameter is $c a .30 \mathrm{~nm}$ ) with a broad distribution of chains per aggregate, which, consequently, causes the size distribution of Cu-NPs to become broad with a larger average size of the NPs.

Optical spectroscopy demonstrates a difference in the assembly mechanisms for irradiated solutions. In the case of aqueous mixtures of PAA and $\mathrm{CuSO}_{4}$ irradiated at $\mathrm{pH}$ 2.9, a weak red coloration already appears at exposition of $10 \mathrm{kGy}$. The exposition in the range 20-40 kGy leads to the increasing intensity of the color. The gradual change of coloration points to the formation of $\mathrm{Cu}-\mathrm{NPs}$ in parallel processes of homogeneous nucleation, growth, and coalescence of clusters (reactions (4)-(6)). The early stages of the assembly process include the fast formation of short-lived 'magic' clusters $\left(\mathrm{Cu}_{2}\right)^{2+}$ and $\left(\mathrm{Cu}_{4}\right)^{2+} \cdot{ }^{33}$ These short-lived clusters do not exhibit bands in the UV-VIS spectra. The calculated yield for $\mathrm{Cu}^{2+}$ reduction $G=1.4$ is in good agreement with the data reported previously. ${ }^{42}$ The reduction potential $E_{0}$ for $\mathrm{Cu}^{2+} / \mathrm{Cu}^{+}$is $-0.15 \mathrm{~V}^{33}$ The hydrated electrons $(G=2.8)$, alcohol radicals $(G=3.2),{ }^{33}$ and even the weak reductant acetaldehyde $(G=3.2)^{22,44}$ with a total yield of 9.2 may act as reducing agents for $\mathrm{Cu}^{2+}$ ions. The obtained finding is reasonably explained by disproportionation of $\mathrm{Cu}^{+}$ (leading to the renewal of $\mathrm{Cu}^{2+}$ ) and oxidation of $\mathrm{Cu}^{+}$(ref. 42) and, particularly, of $\mathrm{Cu}^{0}$ atoms. ${ }^{33,42}$ Appearance of $\mathrm{Cu}^{0}$ atoms at the early stage of irradiation results in the formation of clusters and Cu-NPs (reactions (5)-(7)) already at relatively low doses.

In the case of aqueous mixtures of PAA and $\mathrm{CuSO}_{4}$ irradiated at $\mathrm{pH}$ 4.3, the experimental data clearly demonstrate different stages of Cu-NP assembly. One observes a yellow coloration at a dose of $10 \mathrm{kGy}$ while the sample becomes red in the dose range of 20-40 kGy. The yellow coloration was attributed to the presence of $\mathrm{Cu}_{2} \mathrm{O}-\mathrm{NPs},{ }^{30}$ which precedes the formation of $\mathrm{Cu}$ NPs. The spectrum of the $\mathrm{Cu}_{2} \mathrm{O}-\mathrm{NPs}$ demonstrates an extensive signal in the range of $300-550 \mathrm{~nm}$ with a broad band at 300$400 \mathrm{~nm} .{ }^{33}$ The sample irradiated at a dose of $10 \mathrm{kGy}$ exhibits absorbance within 300-600 $\mathrm{nm}$ and shows a broad band in the UV-VIS spectrum. The latter may be identified as the signal of both $\mathrm{Cu}_{2} \mathrm{O}-\mathrm{NPs}$ and $\mathrm{Cu}-\mathrm{NPs}$. The poorly resolved spectrum of the sample irradiated at $20 \mathrm{kGy}$ (Fig. 4b, spectrum 3) is clearly a superposition of both signals relevant to $\mathrm{Cu}_{2} \mathrm{O}$ and $\mathrm{Cu}$ (the band near $570 \mathrm{~nm}$ and the broad band with the maximum at $420 \mathrm{~nm}$ ). Thus, the experimental data proves the multistage mechanism of the NP formation in the considered systems. The Cu-NPs ripen from preliminarily generated ultrasmall $\mathrm{Cu}_{2} \mathrm{O}$ seeds. It is worth noting that the yellow coloration, similar to our finding, was observed previously at the early stages of the radiation-induced reduction of $\mathrm{Cu}^{2+}$ ions in the solutions containing poly(vinyl alcohol) ( $\mathrm{pH}$ 6.2) and poly(acrylic acid) $(\mathrm{pH} 10.7) .{ }^{42}$ This effect was attributed to the formation of colloidal particles of $\mathrm{CuOH}$, while further irradiation led to Cu-NPs. In any case, all the data reported previously ${ }^{30,33,42}$ show the formation of intermediate particles containing $\mathrm{Cu}^{+}$after reduction of $\mathrm{Cu}^{2+}$ ions in neutral or alkaline media.

The reduction yield of $\mathrm{Cu}^{2+}$ was found to be $G=4.2$ at $\mathrm{pH}$ 4.3, which is much higher than that at $\mathrm{pH}$ 2.9. In this case, the mechanism includes the successive reduction of copper ions (reaction (4)). The yellow coloration, which appears at intermediate doses of irradiation, remains stable for several hours, if the irradiation is stopped at this stage. This means that disproportionation probably does not play a significant role under such conditions. A smaller contribution of processes of $\mathrm{Cu}^{+}$and $\mathrm{Cu}^{0}$ oxidation provides increase in the reduction yield. It should be noted that the highest total reduction yield of $\mathrm{Cu}^{2+}$ $(G=6)$ was found in irradiated solutions of polyethyleneimine with the initial concentration of $\mathrm{Cu}^{2+}$ ions of $10^{-3} \mathrm{M},{ }^{33}$ where the process occurs through a two-stage single-electron reduction (reaction (4)). In the case of the molecularly dispersed state of $\left(\mathrm{PAA}_{N}\right)_{\mathrm{X}}(\mathrm{pH} 4.3)$, the reduction occurs inside nanoreactors, that is, inside macromolecules, with the sizes of 10-15 $\mathrm{nm}$. Meanwhile, for nanoheterogeneous solutions, the reaction rate may be limited by the transport of the reducing species. The complexation of ions may have a crucial effect on the reduction potentials, ${ }^{45}$ thus changing the efficiency of the radiationinduced formation of NPs. The comparison of the reduction yields found for $\mathrm{Cu}^{2+}$ at $\mathrm{pH} 4.3$ and the yield of $\mathrm{e}^{-}$aq $\left(G=2.8^{33}\right)$ for aqueous solutions demonstrates the ability of alcohol radicals or acetaldehyde $(\approx G=3.3 \times 2)$ to reduce $\mathrm{Cu}^{2+}$ ions complexed with carboxylate groups.

EPR spectroscopy strongly suggests that Cu-NPs are formed from the pre-assembled species at the higher $\mathrm{pH}$. The experimental results reveal a specific aggregation of $\mathrm{Cu}^{2+}$ ions. In addition to their complexation with carboxylate groups of the PAAs, we observed a drastic decrease in the intensity of the EPR signal at higher $\mathrm{pH}$-values (Fig. 2). This can be explained by the transition of $\mathrm{Cu}^{2+}$ ions into a non-paramagnetic form, i.e., dinuclear copper complexes with "bridging" $\mathrm{OH}$-groups or 
ultrasmall NPs of $\mathrm{Cu}(\mathrm{OH})_{2}$. Such species predominating in aggregates are known to be "invisible" in the EPR spectra due to strong anti-ferromagnetic interactions. ${ }^{46,47}$

The formation of polynuclear copper complexes with "bridging" OH-groups or NPs of $\mathrm{Cu}(\mathrm{OH})_{2}$ seems extraordinary at such $\mathrm{pH}$ as 4.3 .

$$
m\left(\mathrm{Cu}^{2+}\right)+k\left(\mathrm{OH}^{-}\right)+n\left(\mathrm{COO}^{-}\right) \leftrightarrows\left(\mathrm{Cu}^{2+}\right)_{m}\left(\mathrm{OH}^{-}\right)_{k}\left(\mathrm{COO}^{-}\right)_{n}
$$

However, immobilization of $\mathrm{Cu}^{2+}$ ions inside macromolecules of $\left(\mathrm{PAA}_{N}\right)_{X}$ leads to their high local concentration therein, which may shift the equilibrium (8) to the formation of the ultrasmall $\left(\mathrm{Cu}^{2+}\right)_{m}\left(\mathrm{OH}^{-}\right)_{k}\left(\mathrm{COO}^{-}\right)_{n}$ species.

At higher $\mathrm{pH}$-values, therefore, $\mathrm{Cu}^{2+}$ ions may exist mainly as aggregates incorporated into PAA macromolecules. Apparently, in this case, such small aggregates act as nuclei for the further reduction of $\mathrm{Cu}^{2+}$ ions so that ripening of the Cu-NPs occurs in such ultrasmall preformed $\mathrm{Cu}_{2} \mathrm{O}$ seeds.

$$
\begin{gathered}
\left(\mathrm{Cu}^{2+}\right)_{m}\left(\mathrm{OH}^{-}\right)_{k}\left(\mathrm{COO}^{-}\right)_{n} \rightarrow \mathrm{Cu}_{2} \mathrm{O} \text { seeds } \\
\mathrm{Cu}_{2} \mathrm{O} \text { seeds } \rightarrow \text { Cu-NPs }
\end{gathered}
$$

It is logical to suppose in this case a heterogeneous nucleation, which occurs via reduction of such preassembled species and results in the formation of hydrated $\mathrm{Cu}_{2} \mathrm{O}$ seeds (reaction (9)). The further irradiation leads to transformation of protoxide intermediates to Cu-NPs due to reduction and coalescence processes inside of such macromolecular containers. The optical data (Fig. 4) demonstrate the dominating role of the reaction (9) for the initial stage of the Cu-NP formation (for doses of up to $20 \mathrm{kGy}$ ), the increase of irradiation dose resulting in the prevalence of the process (10).

\section{Conclusions}

The data presented in this work on radiation-induced preparation of the Cu-NPs in solutions of PAA stars provide evidence that the state of $\mathrm{Cu}^{2+}$ ions (bound or unbound to carboxylic groups of the polyelectrolyte) to be reduced decisively controls the size/size distribution of such NPs. For aquacomplexes of $\mathrm{Cu}^{2+}$ ions (unbound state at $\mathrm{pH}$ 2.9), the formation of the $\mathrm{Cu}$-NPs proceeds through homogeneous nucleation caused by the strong, radiation-derived reducing agents. When $\mathrm{Cu}^{2+}$ ions are localized inside PAA stars (bound state at $\mathrm{pH}$ 4.3), the ripening of $\mathrm{Cu}$-NPs is considered to occur from the preformed $\mathrm{Cu}_{2} \mathrm{O}$ seeds apparently derived from ultrasmall clusters $\left(\mathrm{Cu}^{2+}\right)_{m}\left(\mathrm{OH}^{-}\right)_{k}\left(\mathrm{COO}^{-}\right)_{n}$ (heterogeneous nucleation). Such localization and concentrating of $\mathrm{Cu}^{2+}$ ions provides a specific regime for the formation of Cu-NPs. In this case, each PAA star acts as an individual nanoreactor wherein such NPs are generated. The sizes of the resultant $\mathrm{Cu}-\mathrm{NPs}$ are determined by the amount of $\mathrm{Cu}^{2+}$ ions, which can be accommodated within PAA stars with 5 or with 21 arms, each star-shaped macromolecule appearing to give birth to one $\mathrm{Cu}-\mathrm{NP}$ only. Such polyelectrolyte-induced pre-assembly of $\mathrm{Cu}^{2+}$ ions is considered as a prerequisite for the formation of narrowdispersed Cu-NPs at pH-values such as $\mathrm{pH} 4.3$ (which are lower than those already reported in the literature) in the examined systems. The increasing efficiency of the radiation-induced preparation of NPs in the case of heterogeneous nucleation may be explained by the decreasing contribution of the reverse oxidation processes.

\section{Acknowledgements}

The support from the Russian Foundation for Basic Research (project no. 15-03-04886) is gratefully acknowledged.

\section{References}

1 L. M. Bronstein, S. N. Sidorov and P. M. Valetsky, Russ. Chem. Rev., 2004, 73, 501.

2 X. Shi, M. Shen and H. Möhwald, Prog. Polym. Sci., 2004, 29, 987.

3 M. Ballauff and Y. Lu, Polymer, 2007, 48, 1815.

4 Y. Lu and M. Ballauff, Prog. Polym. Sci., 2011, 36, 767.

5 D. V. Pergushov, A. A. Zezin, A. B. Zezin and A. H. E. Müller, Adv. Polym. Sci., 2014, 255, 173.

6 D. Suzuki and H. Kawaguchi, Langmuir, 2006, 22, 3818.

7 L. Manziek, E. Langenmayr, A. Lamola, M. Gallagher, N. Brese and N. Annan, Chem. Mater., 1998, 10, 3101.

8 O. Mergel, A. P. H. Gelissen, P. Wünnemann, A. Böker, U. Simon and F. A. Plamper, J. Phys. Chem. C, 2014, 118, 26199.

9 J. Zhang, S. Xu and E. J. Kumacheva, J. Am. Chem. Soc., 2004, 26, 7908.

10 Z. Lei, X. Wei, L. Zhang and S. Bi, Colloids Surf., 2008, 317, 705.

11 F. Schacher, E. Betthausen, A. Walther, H. Schmalz, D. V. Pergushov and A. H. E. Müller, ACS Nano, 2009, 3, 2095.

12 F. H. Schacher, T. Rudolph, M. Drechsler and A. H. E. Müller, Nanoscale, 2011, 3, 288.

13 M. Zhao, L. Sun and R. M. Crooks, J. Am. Chem. Soc., 1998, 120, 4877.

14 K. Esumi, Top. Curr. Chem., 2003, 227, 31.

15 H. Sun, Z. Gao, L. Yang, L. Gao and X. Lv, Colloid Polym. Sci., 2010, 288, 1713.

16 Y. Bao, G. Shen, H. Liu and Y. Li, Polymer, 2010, 54, 652.

17 J. Yuan and A. H. E. Müller, Polymer, 2013, 51, 4015.

18 Y. Xu, F. A. Plamper, M. Ballauff and A. H. E. Müller, Adv. Polym. Sci., 2010, 228, 1.

19 F. A. Plamper, L. Murtomäki, A. Walther, K. Kontturi and H. Tenhu, Macromolecules, 2009, 42, 7254.

20 F. A. Plamper, H. Becker, M. Lanzendörfer, M. Patel, A. Wittemann, M. Ballauff and A. H. E. Müller, Macromol. Chem. Phys., 2005, 206, 1813.

21 A. B. Zezin, V. B. Rogacheva, V. I. Feldman, P. Afanasiev and A. A. Zezin, Adv. Colloid Interface Sci., 2010, 158, 84.

22 A. A. Zezin, V. I. Feldman, S. S. Abramchuk, V. K. Ivanchenko, E. A. Zezina, N. A. Shmakova and V. I. Shvedunov, Polym. Sci., Ser. C, 2011, 53, 61.

23 R. Kaur, C. Giordano, M. Gradzielski and S. K. Mehta, Chem. - Asian J., 2014, 9, 189. 
24 R. Prucek, L. Kvítek, A. Panáček, L. Vančurová, J. Soukupová, D. Jančík and R. Zbořil, J. Mater. Chem, 2009, 19, 8463.

25 A. Bakar, V. Dyo, A. A. Zezin, S. S. Abramchuk, O. Güven and V. I. Feldman, Mendeleev Commun., 2012, 22, 211.

26 J. P. Ruparelia, A. K. Chatterjee, S. P. Duttagupta and S. Mukherji, Acta Biomater., 2008, 4, 707.

27 S. Brzeziński, G. Malinowska, D. Kowalczyk, A. Kaleta, B. Borak, M. Jasiorski, K. Dbek, A. Baszczuk and A. Tracz, Fibres Text. East. Eur., 2012, 20, 70.

28 S. Park, R. J. Gorte and J. M. Vohs, Appl. Catal., A, 2000, 200, 55.

29 B. Bozzini, L. D’Urzo, M. Re and F. De Riccardis, J. Appl. Electrochem., 2008, 3, 356.

30 Y. Wang and T. Asefa, Langmuir, 2010, 26, 7469.

31 P. Pulkkinen, J. Shan, K. Leppänen, A. Känsäkoski, A. Laiho, M. Järn and H. Tenhu, ACS Appl. Mater. Interfaces, 2009, 1, 519. 32 J. Belloni, Catal. Today, 2006, 113, 141.

33 B. G. Ershov, Russ. Chem. Bull., 1994, 43, 16.

34 S. S. Joshi, S. F. Patil, V. Lyer and S. Mahumuni, Nanostruct. Mater., 1998, 10, 1135.

35 H. Remita, I. Lampre, M. Mostafavi, E. Balanzat and S. Bouffard, Radiat. Phys. Chem., 2005, 72, 575.

36 J. H. Hubbel and S. M. Seltzer, Tables of X-ray mass attenuation coefficients and mass energy-absorption coefficients from
$1 \mathrm{keV}$ to $20 \mathrm{MeV}$ for elements $Z=1$ to 92 and 48 additional substances of dosimetric interest, http://www.nist.gov/pml/ data/xraycoef.

37 N. M. Kabanov, A. I. Kokorin, V. B. Rogacheva and A. B. Zezin, Vysokomol. Soedin., Ser. A, 1979, 11, 209.

38 M. P. Trubitsyn, M. D. Volnianskii and A. Yu. Kudzin, Ferroelectrics, 2005, 316, 121.

39 J. Hambrock, R. Becker, A. Birkner, J. Weiss and R. A. Fischer, Chem. Commun., 2002, 68.

40 J. D. Hanawalt, H. W. Rinn and L. K. Frevel, Ind. Eng. Chem., Anal. Ed., 1938, 10, 467.

41 R. W. Murray, Chem. Rev., 2008, 108, 2688.

42 J. Khatouri, M. Mostafavi, J. Amblard and J. Belloni, Chem. Phys. Lett., 1992, 191, 351.

43 P. J. Wardman, J. Phys. Chem. Ref. Data, 1989, 18, 1637.

44 A. A. Zezin, V. I. Feldman, E. A. Zezina, S. I. Belopushkin, E. V. Tsybina, S. S. Abramchuk and S. B. Zezin, High Energy Chem., 2011, 45, 99.

45 E. Gachard, H. Remita, J. Khatouri, J. Belloni, B. Keita and L. Nadjo, New J. Chem., 1998, 22, 1257.

46 P. A. Berger and J. F. Roth, J. Phys. Chem., 1967, 71, 4307.

47 R. C. Holz, J. M. Bradshaw and B. Bennett, Inorg. Chem., 1998, 37, 1219. 